\title{
THIN FILM METALLIZATION FOR MICRO-BIMETALLIC ACTUATORS
}

\author{
Jonathan Gorrell \\ Motorola, 5005 E. McDowel Road, Phoenix, AZ 85008 \\ Paul Holloway and Kenneth Shannon, III \\ University of Florida, Department of Materials Science and Engineering \\ Gainesville, FL 32611
}

\begin{abstract}
In this study, eleven different thin film metallization systems were evaluated for use in micro-bimetallic actuators for microelectromechanical structures. These films were evaporated or sputtered onto silicon wafers. The film stress and stress relaxation were determined by measuring changes in the wafer curvature.

Bimetallic actuator may be operated to generate either force or displacement. A figure of merit was developed to aid in the selection for either mode of operation. The displacement mode is dominated by the coefficient of thermal expansion, while the force mode is dependent on both the Young's modulus and the coefficient of thermal expansion of the active layer material. In both modes the maximum displacement or force is limited by the material's yield strength.

Three aluminum alloy thin films were studied. The 5052 aluminum alloy films showed that solid solution strengthening can double the yield strength of a thin film. The T201 aluminum alloy films showed that precipitates can increaseyield strength by 2.5 times. The 2090 alloy film oxidized during the first heating and is not of interest for bimetallic actuators.

Nickel, copper, titanium, and manganese films all oxidized on their first heating to $350^{\circ} \mathrm{C}$. The copper film also oxidized at $50^{\circ} \mathrm{C}$ over 48 hours and changed the stress state versus time. Thus oxidation resistance is a significant requirement for materials in thermal actuators.

$\mathrm{Al}_{3} \mathrm{Ti}$ intermetallic films were also evaluated and showed no stress relaxation at $450^{\circ} \mathrm{C}$, plastically deformed only above $500^{\prime \prime} \mathrm{C}$, had limited oxidation up to $800^{\circ} \mathrm{C}$ and had a room temperature residual stress of $950 \mathrm{MPa}$, nearly 5 time greater than the $\mathrm{Al}-\mathrm{Si}-\mathrm{Cu}$ alloy film. Thus $\mathrm{Al}_{3} \mathrm{Ti}$ is a very promising high temperature bimetallic metallization.
\end{abstract}

\section{INTRODUCTION}

Micro-Bimetallic actuators have been shown to be an effective actuation mechanism for MEMS devices [1,2,3]. They can produce a large force over a large displacement, are easily manufactured, and can potentially operate in severe environments. The performance of a bimetallic actuator is determined, to a large degree, by the mechanical properties of the materials of which they are constructed. The reason for this dependence on the mechanical properties of the materials is that the force or displacement generated in a bimetallic actuator is caused by the interaction of the materials in the device. The principle of actuation using a bimetallic element is shown in Fig. 1 for a cantilevered strip. In this example, the active layer, $\mathrm{Al}$ with a high coefficient of thermal expansion $\left(\mathrm{CTE}=25 \mathrm{ppm} /{ }^{\circ} \mathrm{C}\right)$, is deposited or bonded to the passive layer, $\mathrm{Si}$ with a low coefficient of thermal expansion $\left(2.3 \mathrm{ppm} /{ }^{\prime \prime} \mathrm{C}\right)$. When the temperature of the couple is increased the $\mathrm{Al}$ layer expands more than the $\mathrm{Si}$ layer, changing the shear stress between these two layers which cases the couple to

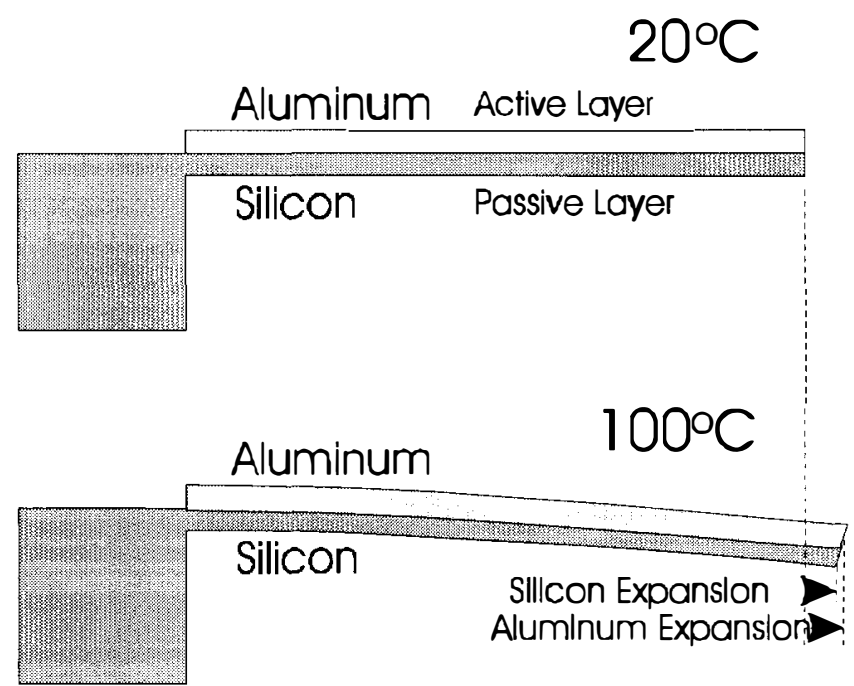

Figure 1. Diagram of a bimetallic couple showing the curvature at $20^{\circ} \mathrm{C}$ in the absence of stress and the curvature at $100^{\circ} \mathrm{C}$ due to the extrinsic stress generated from the differences in the CTEs.

deflect down. Conversely, for a temperature reduction the Al layer contracts more than the Si layer causing the couple to deflect upwards.

By examining the equations that describe the performance of a bimetallic actuator, developed by Timoshenko [4], the effects of materials properties can be evaluated. For a bimetallic strip the curvature $k$, which is equivalent to displacement, is given by:

$$
k=\frac{3}{2} \cdot \frac{\left(\alpha_{1}-\alpha_{2}\right)}{h} \cdot \Delta \mathrm{T}
$$

where $\Delta \mathrm{T}$ is the change in temperature, $\alpha_{1}$ and $\alpha_{2}$ are the CTE's of the active and passive layers and $h$ is the thickness of the strip. As can be seen from this equation it is the difference in the thermal expansion of the two layers that determines the curvature for a given temperature change and strip thickness. Given that the passive layer will be silicon for most MEMS bimetallic actuators the active layer material should have the largest CTE possible. For the case of force generation, equation 2 gives the restraining force $R$ needed to stop a bimetallic strip from bending, which is the maximum force generated by the strip where $L$ is the length of the device and $E_{1}$ and $E_{2}$ are the Young's moduli for the active and passive layers. As can be seen, the restraining force is now proportional to the product of the active layers Young's modulus and CTE. Thus for maximum force a

$$
R=\frac{9}{4} \cdot \frac{\left(\frac{E_{1}+E_{2}}{2}\right) \cdot \frac{h^{3}}{12}}{h \cdot L} \cdot\left(\alpha_{1}-\alpha_{2}\right) \cdot \Delta \mathrm{T} .
$$


material with a high modulus and CTE is desired for the active layers. It has also been shown by Jerman [5] that these same trends hold for a bimetallic disk.

In both equation it is assumed that the materials behave elastically. Any plastic deformation of either layer would result in a reduction of force and or displacement of and actuator and has been seen in bimetallic actuators of pure aluminum or $\mathrm{Al}-\mathrm{Si}-\mathrm{Cu}$ on silicon [5]. In addition, Draper and Hill [6] have shown that the biaxial stress in bimetallic couples can relax at near room temperature. Thus, while not included in the equation the describe the performance of a bimetallic strip, a materials yield strength determines the operating range of an actuator.

It can be shown that to a first approximation a material's thermal expansion is inversely proportional to its Young's modulus which is in turn proportional to its yield strength [7]. For an actuator design to produce force this does not create a problem as a material with a moderate CTE, high Young's modulus and high yield strength can be selected (ie Nickel, Stainless Steal). However, for an actuator designed for displacement, material selection is more difficult. Materials with high CTE's generally have lower yield strength and are more susceptible to plastic deformation, creep and stress relaxation [8]. Materials with high CTE's ( $\mathrm{Al}, \mathrm{Mg}$ ) can be strengthen by a number of techniques $[9,10]$. However, the effectiveness of these strengthening techniques have not been extensively studied in thin films. Therefore, this studies examines the effectiveness of two bulk strengthening mechanism in thin films.

In addition to the stresses that are generated due to the difference in thermal expansion, called extrinsic stress, stress can also develop during the deposition process, called the intrinsic stress. Intrinsic stress from deposition has been discussed by Thorton and Hoffman [11,12] and Dorner and Nix [13]. These stresses may be varied by changing the conditions of deposition of the thin films [1113]. For the deposition of high Young's modulus materials the intrinsic stresses must be controlled during the deposition process to limit the stresses between the active and passive layers. Intrinsic stresses in high modulus materials can be high enough to damage MEMS devices. However, for high CTE material such as aluminum the extrinsic stresses tend to dominate over the temperatures that the actuators operate in.

There is also a desire for actuators to work at elevated temperatures and in severe environments. For these requirements a number of other elemental metals and intermetallics were evaluated. Intermetallics constitute a class of material that is a cross between metals and ceramics [14] and may have very high strength and resistant to oxidation at elevated temperature.

\section{EXPERIMENTAL PROCEDURES}

Thin films $\sim 1 \mu \mathrm{m}$ thick were deposited onto (100) oriented 4" diameter Si wafers with a $100 \mathrm{~nm}$ thermally grown $\mathrm{SiO}_{2}$ layer on the surface. The wafers were cleaned using the RCA procedure prior to deposition. The samples were loaded into a vacuum system and pumped to less than $3 \times 10^{-7}$ Torr, followed by deposition from an 8" DC planar magnetron source at $5 \mathrm{KW}$ in $8 \mathrm{mTorr}$ of $\mathrm{Ar}$ with the wafers at $100^{\circ} \mathrm{C}$. Films of commercial alloys designated T201, 5052 and 2090 were deposited (see table 1 for chemical composition). The sputter targets were cut from sheet stock. Copper gold intermetallic thin films were sputter deposited by alternating layers of pure gold and copper. The other elemental metals and the $\mathrm{Al}_{3} \mathrm{Ti}$ intermetallic were deposited by electron beam evaporation using $99.999 \%$ pure material. The $\mathrm{Al}_{3}$ Ti intermetallic thin films were grown by alternating depositions of pure $\mathrm{Al}$ and $\mathrm{Ti}$. The electron beam evaporation was performed in a diffusion pumped, liquid ni- trogen trapped vacuum system operated at a base pressure of $5 \times 10^{-7}$ Torr. During deposition the pressure typically rose to $5 \times 10^{-6}$ Torr and the substrate was heated to $150^{\circ} \mathrm{C}$.

The stress and stress relaxation in the bimetallic couples was determined by using a Tencor FleXus model 2320. This instrument uses an optical lever to measure the curvature of the sample before and after deposition of the film and during temperature cycles ranging from $-60^{\circ} \mathrm{C}$ to $500^{\circ} \mathrm{C}$. The stress in the film is then calculated using Stoney's equation [18]. Unless otherwise stated, all temperature cycles were performed a $1^{\circ} \mathrm{C} /$ minute. For the isothermal stress relaxation test, the samples were first taken to $300^{\prime \prime} \mathrm{C}$, held at this temperature for 30 minutes, returned to $20^{\circ} \mathrm{C}$, then heated to the testing temperature. The samples were held at temperature for 48 hours with measurements being taken every 15 minutes. Environmental stability studies of the metallizations were limited to studies of the oxidation resistance [15].

\section{RESULTS AND DISCUSSION}

For a general discussion of the aluminum alloy, and those used in this study, see reference [16]. The Al-Si-Cu alloy was developed for VLSI interconnect metallization [17]. This alloy was designed to reduce "spiking of the aluminum into the silicon" cause by silicon diffusion into the aluminum, and to reduce electromigration. The Al-Si-Cu alloy was not developed for strength in contrast to the other aluminum alloys examined in this study. The 5052 alloy used $\mathrm{Mg}$ to solid solution strengthen the alloy. Solid solution strengthening is stable over a wide temperature range and is a homogenous alloy. The $\mathrm{T} 201$ alloy is strengthen with $\mathrm{Cu}$ to form $\boldsymbol{\theta} \mathrm{Al}_{2} \mathrm{Cu}$ precipitates that are stabilized to higher temperatures by the addition of the $\mathrm{Ag}$. The $\mathrm{Mg}$ and $\mathrm{Mn}$ alloying elements provide solid solution strengthen to the T201 alloy. The 2090 alloy is strengthen by the formation of $\mathrm{Al}_{2} \mathrm{Li}-\mathrm{Cu}$ precipitates. In the commercial alloys, $\mathrm{Zr}, \mathrm{Ti}$ and $\mathrm{Cr}$ are added to stabilize grain structure.

The stress versus temperature plot for pure aluminum and the $\mathrm{Al}-\mathrm{Si}-\mathrm{Cu}$ alloy are shown in figure 2. Of interest in this plot is the linear dependence of stress versus temperature during the heating cycle. When stress is linearly dependent upon temperature, plas-

TABLE 1

Materials tested, deposition thickness and composition/purity

\begin{tabular}{|c|c|c|}
\hline Material & $\begin{array}{c}\text { Deposited Thickness } \\
\mu \mathrm{m}\end{array}$ & Composition or Purity, (wt. \%) \\
\hline T201 Aluminum & 1.3 & $\begin{array}{c}\mathrm{Al}-4.6 \mathrm{Cu}-0.57 \mathrm{Ag}-0.36 \mathrm{Mn}- \\
0.2 \mathrm{Mg}-0.27 \mathrm{Ti}\end{array}$ \\
\hline 5052 Aluminum & 1.3 & $\mathrm{Al}-2.5 \mathrm{Mg}-0.25 \mathrm{Cr}$ \\
\hline 2090 Aluminum & 1.3 & $\mathrm{Al}-2.57 \mathrm{Cu}-2.1 \mathrm{Li}-0.12 \mathrm{Zr}$ \\
\hline Nickel & 0.8 & 99.98 \\
\hline Titanium & 0.55 & 99.99 \\
\hline Manganese & 0.4 & 99.9 \\
\hline Copper & 0.9 & 99.9 \\
\hline $\mathrm{Al}_{3} \mathrm{Ti}$ & 0.4 & Al-99.99, Ti-99.99 \\
\hline $\mathrm{Cu}_{3} \mathrm{Au}$ & 1.3 & $\mathrm{Cu}-99.99 \mathrm{Au}-99.99$ \\
\hline $\mathrm{CuAu}$ & 1.3 & Cu-99.99 Au-99.99 \\
\hline $\mathrm{CuAu}_{3}$ & 1.3 & Cu-99.99 Au-99.99 \\
\hline
\end{tabular}


tic deformation is not occurring and the film could be used in a bimetallic actuator. For pure aluminum, this linear region goes from 150 $\mathrm{MPa}$ at room temperature to near $-25 \mathrm{MPa}$ (compression) at $125^{\circ} \mathrm{C}$. The linear region is only slightly larger for the $\mathrm{Al}-\mathrm{Si}-\mathrm{Cu}$ alloy, going from $200 \mathrm{MPa}$ at room temperature to $-25 \mathrm{MPa}$ at $175^{\circ} \mathrm{C}$, a $225 \mathrm{MPa}$ region. In contrast figures 3 and 4 show the stress temperature curves for the 5052 alloy and the T201 alloy. Both of these alloys show a much larger linear region with the 5052 alloy being linear from 300 $\mathrm{MPa}$ at room temperature to near $-25 \mathrm{MPa}$ at $225^{\circ} \mathrm{C}$, and the T201 alloy going from 400MPa to -50MPa. The 5052 and T201 alloys would increase the operation range of a bimetallic actuator as compare with pure aluminum and $\mathrm{Al}-\mathrm{Si}-\mathrm{Cu}$ alloy. The 2090 alloy oxidized on the first temperature cycle and is therefore not useful for thermal actuation.

In addition to plastic deformation, stress relaxation is also a concern for thermal actuation. Figure 5 show the isothermal stress relaxation cure for a T201 alloy film at $100^{\circ} \mathrm{C}$ over 48 hours. These data were collected for the T201 and 5052 alloy films at 50, 75, 100, 125 and $150{ }^{\circ} \mathrm{C}$, and for the pure aluminum and $\mathrm{Al}-\mathrm{Si}-\mathrm{Cu}$ films at $50^{\circ} \mathrm{C}$. These data showed that the percentage of the total stress which relaxed in T201 and 5052 alloy films was much less than that for the pure aluminum and $\mathrm{Al}-\mathrm{Si}-\mathrm{Cu}$ alloy [7]. In addition, the room temperature stress in the 5052 alloy could be reduced to $125 \mathrm{MPa}$ by cooling a sample to $-196^{\circ} \mathrm{C}$ [19]. At this lower stress the films showed no isothermal stress relaxation. However, if the film was heated again to $350^{\circ} \mathrm{C}$ the residual stresses returned to the same value as before cooling with liquid nitrogen. This cooling procedure has been shown

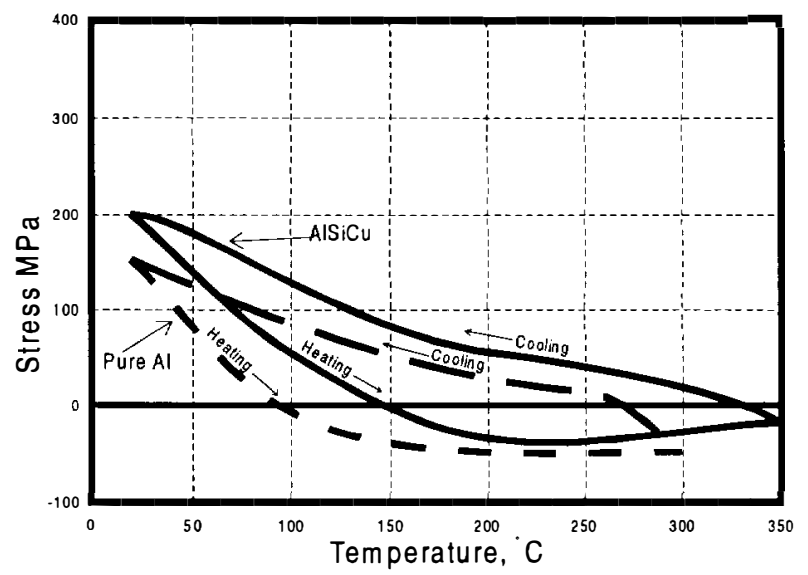

Figure 2. Stress temperature plot for pure aluminum and $\mathrm{Al}-\mathrm{Si}-\mathrm{Cu}$ alloy films.

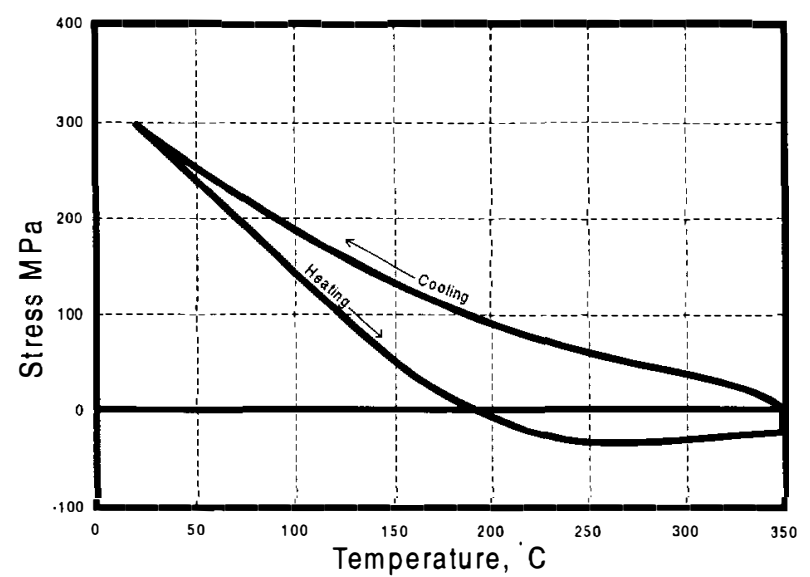

Figure 3. Stress temperature plot for 5052 aluminum alloy films.

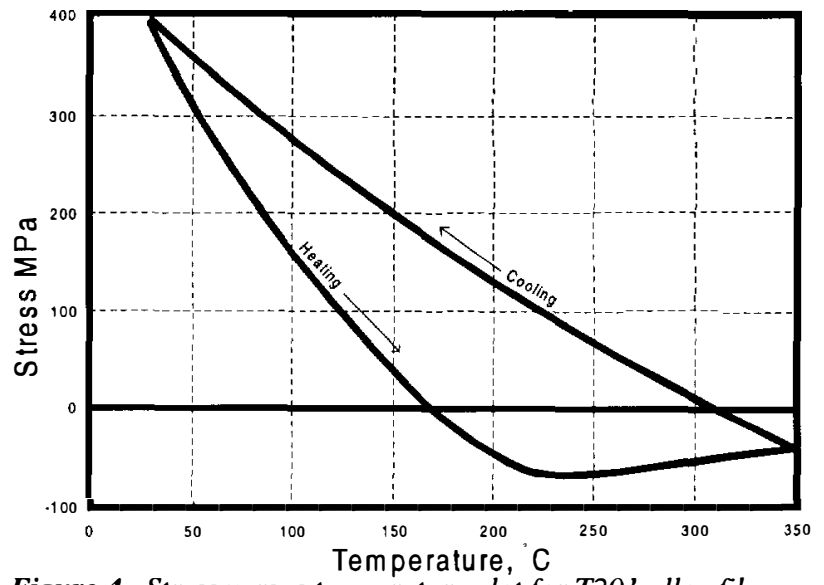

Figure 4. Stress versus temperature plot for T201 alloy film.

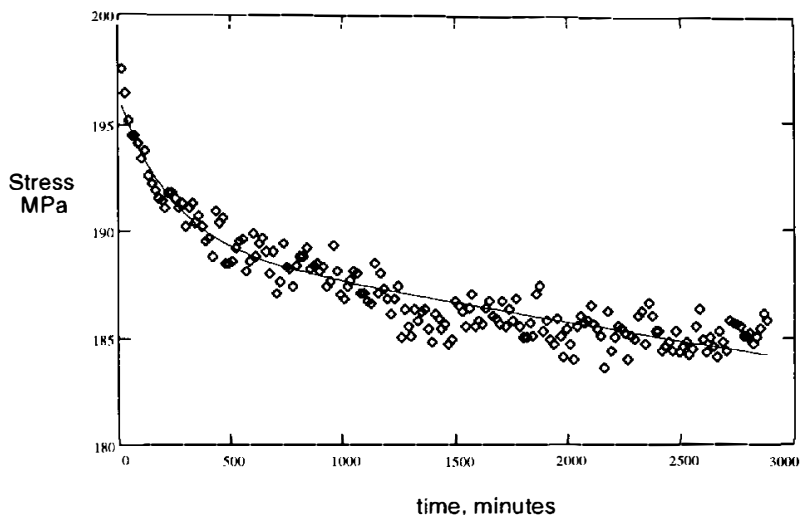

Figure 5. Isothermal stress relaxation for T201 alloy film at $100 T^{\circ} \mathrm{C}$.

to reduce biaxial stress in pure aluminum and $\mathrm{Al}-\mathrm{Si}-\mathrm{Cu}$ alloy films [19], but did not change the stress in the T201 samples.

The stress versus temperature plot for the $\mathrm{Al}_{3} \mathrm{Ti}$ intermetallic film is shown in figure 6. This film was deposited in layers. On the first heating, the layers began to interdiffuse at $350^{\circ} \mathrm{C}$, resulting in a less compressive stress. On subsequent heating to $500^{\circ} \mathrm{C}$ the stress temperature curve was linear and without hysteresis. Samples were then heated to $800^{\circ} \mathrm{C}$, and they plastically deformed above $550^{\circ} \mathrm{C}$. There was also a slight increase in the oxide thickness after this temperature, but the $\mathrm{Al}_{3} \mathrm{Ti}$ intermetallic films are remarkably stable. The copper gold intermetallic films were not as stable. These films oxidized upon there first heating and are not useful for this application.

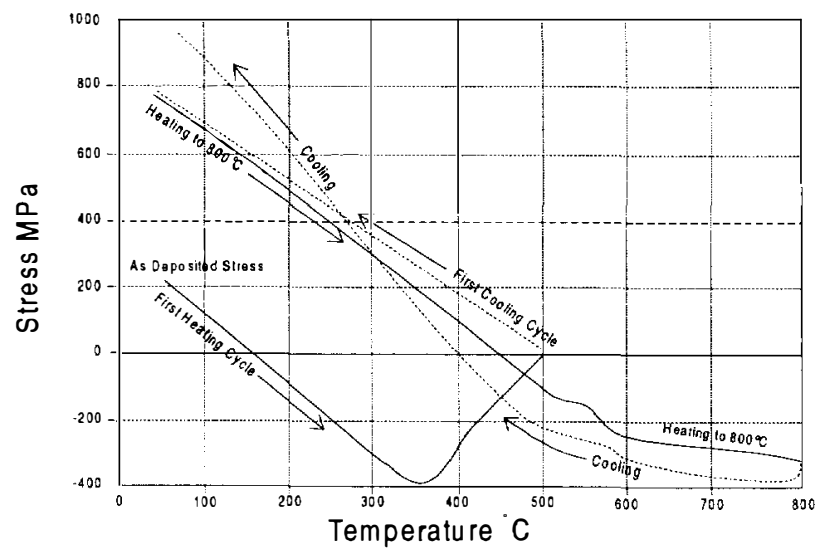

Figure 6. Stress versus temperature plot of Al3Ti intermetallic thin film. 
In addition to the aluminum alloys and intermetallics four other metals were evaluated: copper, nickel, titanium and manganese. Figure 7 shows the initial stress temperature plot for a titanium film. At $350^{\circ} \mathrm{C}$ the film oxidized, causing the large change from tensile to compressive stress. All the other elemental metals had similar results [7]. A copper film was tested at $50^{\prime \prime} \mathrm{C}$ for 48 hours. As shown in figure 8 , it showed significant stress relaxation and oxidized severely, changing from compressive to tensile stress during the relaxation test.

\section{FIGURE OF MERIT}

Given the complexity of selecting a material for the active layer to satisfy a number of different requirement, a figure of merit was develop to assist in materials selection. Equation 3 gives the formulation of the figure of merit, FOM, where MHT is a constant based on the type of material ( 0.4 of most metals, 0.65 for intermetallics), MOT is maximum operating temperate, MP is the melting point of the material in degrees Kelvin, CTE is the coefficient of thermal expansion, $\mathrm{E}$ is the Young's modulus, and FD is a constant

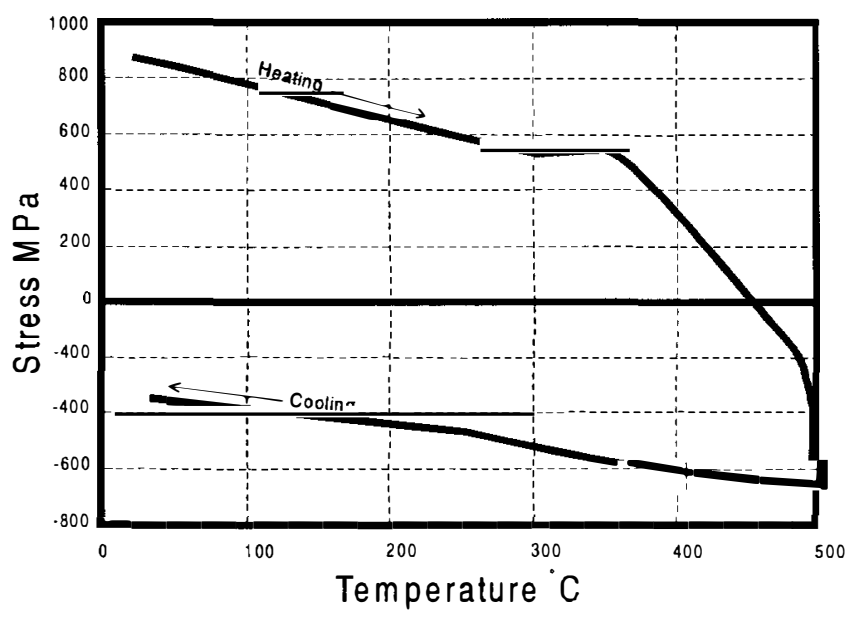

Figure 7. Stress versus temperatue plot for a titamium thin film.

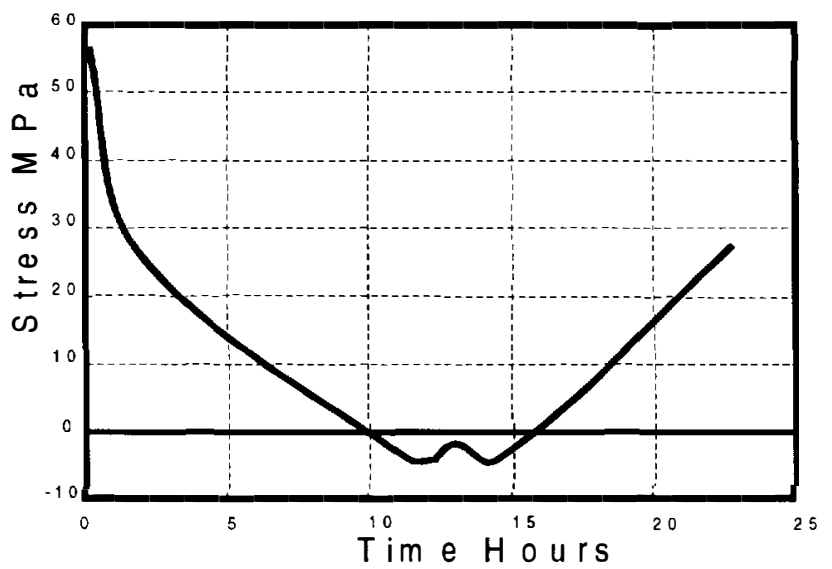

Figure 8. Isothermal stress plot for copper film at $50^{\prime \prime} \mathrm{C}$

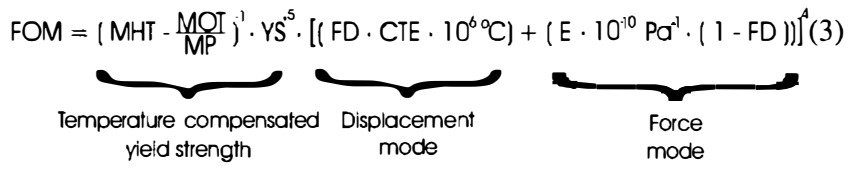

varying from 0 to 1 (zero to maximize force, and one to maximizing displacement). Based on this $\mathrm{FOM}, \mathrm{Al}_{3} \mathrm{Ti}$ is the most attractive material for force and T201 is the most attractive for displacement (maximum temperature of $200^{\circ} \mathrm{C}$ ).

\section{CONCLUSIONS}

This study has shown that the strengthening mechanism used in bulk metals can be effective at increasing the yield strength of thin films. Strengthened thin films can significantly increase the performance of a bimetallic actuator. Intermetallic $\mathrm{Al}_{3} \mathrm{Ti}$ films were found to perform well at elevated temperatures and showed little or no stress relaxation. Oxidation was found significantly affect the other elemental metals and the copper gold intermetallics reducing there usefulness for this application.

\section{ACKNOWLEDGEMENTS}

This work was supported by DARPA contract DABT6395-C-0038 through ICSensors. Contributions from Hal Jerman (formerly at ICSensors), Vladimir Vaganov, and Nicolai Belov are gratefully acknowledged.

\section{REFERENCES}

1. M.Madou, Fundamentals of Microfabrication (CRC Press LLC, New York, 1997).

2. H. Jerman, Micromach Microeng, 4 ,210 (1994).

3. P.W. Barth, C.C. Beatty, L.A. Field, J.W Baker and G.B. Gordin, Solid-State Sensor and Actuator Workshop Hilton Head, SC, June 13-16, P.248 (1994).

4. S. Timoshenko, J. Opt. Soc. AM., 11, 23 (1925).

5. H. Jerman, personal communications (1995).

6. B.L. Draper and T.A. Hill, J. Vac. Sci. Technol., B9,1956 (1991).

7. J.F. Gorrell, “ Thin Film Metallization for Micro-Bimetallic Actuators”. Ph.D. Dissertation, University of Florida, June, 1997.

8. R.W. Cahn and P. Haasen, Physical Metallurgy $3^{\text {rd }}$ edition (North-Holland Physics Publishing, New York, 1983).

9. C.R. Brooks, Heat Treatment, Structure and Properties of Nonferrous Alloys (American Society for Metals, Metals Park Ohio, 1982).

10. R.E. Reed-Hill and R. Abbaschien, Physical Metallurgy Principles (PWS-Kent Publishing Company, Boston, 1992).

11. J.A. Thorton and D.W. Hoffman, Thin Solid Films, 171, 5 (1989).

12. R.W. Hoffman, Thin Solid Films, 34, 185 (1975).

13. M.F. Dorner and W.D Nix, Crit Rev. Solid State Materials Science, 14, 225 (1988).

14. D.P. Pope, Mat. Res. Symp. Proc., 81, 4 (1987).

15. J.H. Westbrook and R.L. Fleischer, Intermetallic Compounds Principles and Proctice (John Wiley \& Son, New York, 1995).

16. Metals Handbook, Volume 2: Properties and Selection: Nonferrous Alloys and Special Purpose Materials, Tenth Edition (American Society for Metals, Metals Park Ohio, 1982).

17. J. W. Mayer and S.S. Lau, Electronic Materials Science: For Integrated Circuits in Si and GaAs (Macmillan Publishing Company, New York, 1990).

18. G.G. Stoney, Proc. Roy. Soc. London, 82, 172 (1909).

19. F. Baldwin, P.H. Holloway, M. Bordelon and T.R. Watkins, Mat. Res. Soc. Symp. Proc., 309, 261 (1994). 